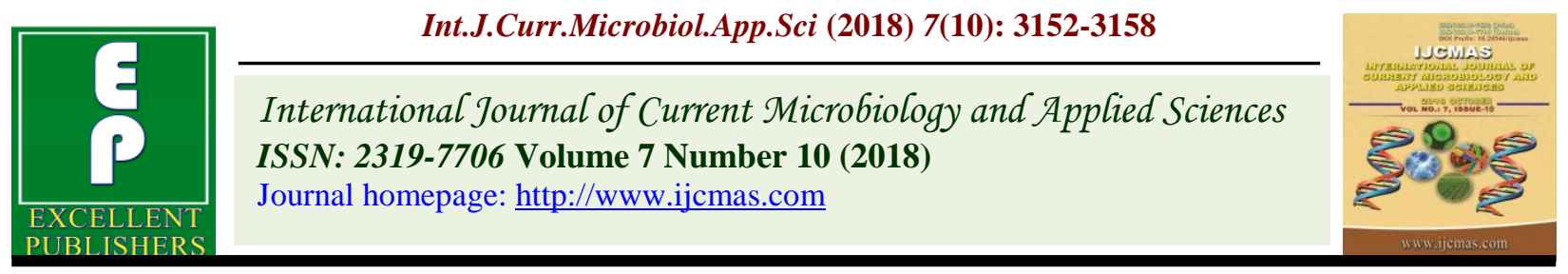

Original Research Article

https://doi.org/10.20546/ijcmas.2018.710.365

\title{
Quantitative GXE Interaction Estimation in the Germplasm of Pearl Millet [Pennisetum glaucum (L.) R. Br.] in the Hot Arid Climate of Rajasthan
}

\author{
Om Vir Singh, Kartar Singh and Neelam Shekhawat ${ }^{*}$
}

National Bureau of Plant Genetic Resources, Regional Station, Jodhpur, India

*Corresponding author

\section{A B S T R A C T}

\section{Keywords}

Pearl millet, Hot arid climate, Accession x Environment interaction, Crossover and non-crossover interaction, Regression analysis

Article Info

Accepted: 24 September 2018 Available Online: 10 October 2018
Twenty nine accessions of pearl millet along with checks were evaluated in five seasons i.e. Kharif of the year 2012, 2013, 2014, 2015 and 2016 for eight quantitative traits and data were subjected to regression analysis and also the analysis to detect the presence of crossover and non-crossover interactions. Three accessions IC 426855, IC 325181 and IC 139920 were identified to be promising using regression analysis, whereas five accessions IC 325794, IC 426855, IC 369859, IC 329055 and IC 325181 against standard check RAJ. 171 were identified as potential ones by using crossover and non-crossover interactions concept. Of these accessions IC 426855 and IC 325181 have been identified as high yielding accessions having specific adaptability and responsiveness to specific environment both by regression analysis and crossover and non-crossover interactions concept.

\section{Introduction}

Productivity of pearl millet in the hot- arid climate has always not been comparable to the normal climatic conditions. Pearl millet is cultivated during Summer and Kharif seasons in India but in western Rajasthan pearl millet is cultivated during kharif season only due to limitations of the irrigation water. A plenty of good hybrids and open pollinated varieties have been developed by the public and private sectors for cultivation in India but there are only a few hybrids for the western Rajasthan where annual rainfall is very limited $(<300$ $\mathrm{mm}$ ) and climate is very hot and dry. In some areas specially in Barmer and Jaisalmer districts of western Rajasthan still farmers are growing their low yielding land races, which are adapted to such type of climatic conditions but productivity of these land races is very low (< $100 \mathrm{Kg} / \mathrm{ha}$ ). To enhance productivity and production of pearl millet it is advocated that breeders should look for environment specific varieties/hybrids which are capable of giving high yield. This becomes more important in case of pearl millet to breed for their responsiveness to specific environment as it is grown in a wide range of climatic conditions. Keeping in view the above, the present investigation was carried out over five years during Kharif season in the hot- arid climate of Rajasthan to identify suitable accessions of pearl millet using regression analysis (Eberhart and Russell, 1966 and Perkins and Jinks, 1968) and cross and non-crossover interactions concept (Gail and Simon, 1985). 
Earlier information on this aspect in pearl millet germplasm is not available.

\section{Materials and Methods}

Twenty nine diverse accessions collected in different years from different place from Rajasthan and adjoining states along with best performing local checks i.e. RAJ 171 (OPV) and two hybrids HHB 67 and RHB 173were evaluated in a randomized block design with three replications over five years in 2012, 2013, 2014, 2015 and 2016 during i.e. Kharif seasons at Regional Station of National Bureau of Plant Genetic Resources, Jodhpur. Thus, evaluation was done broadly in five environments. In each environment plots consisted of four rows of $3 \mathrm{~m}$ length with row to row and plant to plant distances of 45 and $15 \mathrm{~cm}$, respectively. Recommended doses of $\mathrm{P}_{2} \mathrm{O}_{5} @ 30 \mathrm{~kg} / \mathrm{ha}$ and $\mathrm{N}_{2} @ 40 \mathrm{~kg} / \mathrm{ha}$ were also applied at the time of sowing and side dressing at the seedling age of 25 days. Recommended packages of practices were followed to raise good crop. The data were recorded on five randomly taken plants from middle rows of each plot in each environment on seed yield/plant (g), biological yield/plant (g), harvest index (direct values were used for statistical analysis), number of effective tillers per plant, plant height, flag leaf area, ear head length $(\mathrm{cm})$ and days to $50 \%$ flowering and data were analyzed separately for each environment. Adjusted progeny means were used for the combined analysis and for the traits exhibiting the presence of $\mathrm{g} x \mathrm{e}$ interaction. Regression analysis and analysis to detect the presence of crossover and noncrossover interactions were carried out as per Eberhart and Russell (1966), Perkins and Jinks (1968) and Gail and Simon (1985).

\section{Results and Discussion}

Analysis of variance revealed significant differences among accessions for the eight traits in all five years. The combined analysis revealed the presence of $\mathrm{g} x$ e interaction for seed yield/plant (g), biological yield/plant (g), harvest index, number of effective tillers per plant, plant height, flag leaf area, ear head length $(\mathrm{cm})$ and days to $50 \%$ flowering. Regression analysis enables breeders to select desirable accessions with respect to the responsiveness and stability in different environments. In the studied materials the accessions IC 139920IC 325181 and IC 426855 had above average performance and responsiveness with respect to seed yield/plant using regression analysis (Table 1). Among these high yielding accessions IC 139920 can be designated as stable ones with average responsiveness.

Though the accessions IC 325181 and IC 426855 are above average yielder and also have shown above average responsiveness coupled with instability. Accession IC 325181 and IC 426855 were highest yielder during Kharif 2013 and Kharif 2015 respectively followed by IC 139920 (Kharif, 2012) and were significantly superior to the best check RAJ 171.

The accession IC 325181 had above average performance along with instability for seed yield/plant (g), biological yield/plant (g), harvest index, number of effective tillers per plant, plant height, ear head length $(\mathrm{cm})$ and days to $50 \%$ flowering being the best performance of this accession for these traits again in Kharif 2013 and accession IC 426855 showed above average performance along with instability for seed yield/plant (g), biological yield/plant $(\mathrm{g})$, harvest index, ear head length $(\mathrm{cm})$ and days to $50 \%$ flowering for these traits again during Kharif 2015.

The regression technique describes the response pattern of individual accession without differentiating the kind of $\mathrm{g} x \mathrm{e}$ interaction involving change in magnitude of 
response or direction among the accessions (Baker, 1988; and Virk and Mangat 19915). Baker (1988) described a test, which was initially proposed by Gail and Simon (1985) and illustrated its application to test the kind of interaction in crop plants.

The concept of crossover and non-crossover interaction is important in decision making relating to crop improvement strategies (Baker, 1988), since the presence of crossover interaction is substantial evidence in favour of breeding for specific adaptation to certain situations. Baker (1988) further suggested that in the absence of crossover interaction there is little substance for argument in the favour of breeding for adaptation to specific environment. The accessions exhibiting crossover interaction against a standard variety can be said to have specific adaptability and can replace that standard variety in the specific environments.

The existence of prior scientific basis to explain crossover interaction is crucial (Peto, 1982). Thus, it is advantageous to define the varietal combinations among which one has to look for qualitative interaction in advance. There will be enormous multiplicity of all possible varietal pairs for detection of crossover interaction if there is no prior basis for comparison.

Such a practice will greatly increase the experiment-wise error rate. In the present case the new accessions were therefore, compared with the best check RAJ. 171 for detection of crossover interaction since the aim was to find a suitable alternative to RAJ. 171.

The $\mathrm{H}$ (heterogeneity of response) and Q+ and Q- (for the presence of crossover interaction) against the standard variety RAJ. 171 were estimated for all the 28 accessions for the traits exhibiting the presence of $\mathrm{g} x \mathrm{e}$ interaction, i.e., seed yield/plant (g), biological yield/plant (g), harvest index, number of effective tillers per plant, plant height, flag leaf area, ear head length $(\mathrm{cm})$ and days to $50 \%$ flowering and their significance was tested (Baker, 19884). The accession exhibiting either significant $\mathrm{H}$ or $\mathrm{Q}+$ and $\mathrm{Q}-$ are given in Table 2. For seed yield/plant $H$ was significant for the 26accessions against RAJ. 171. The presence of crossover interaction was observed for 24 accessions namely IC 285200, IC 325181, IC 323993, IC 325740, IC 325794, IC 370475, IC 369836, IC 369859, IC 329028, IC 329055, IC 329076, IC420312, IC 420345, IC 373424, IC 373504, IC 373564, IC 449485, IC 577599, IC 577625, IC 577642, IC 426855, IC 426876, IC 426908 and IC 329909 against RAJ. 171.

The 22 accessions i.e. IC 145316, IC 285176, IC 285200, IC 325181, IC 323993, IC 325740, IC 325794, IC 325835, IC 333121, IC 369836, IC 369859, IC 329028, IC 329055, IC420312, IC 373504, IC 373564, IC 449485, IC 577599, IC 577642, IC 426855, IC 426876 and IC 329909 exhibited the presence of crossover interaction for biological yield/plant and twenty nine accessions namely, IC 145316, IC 285176, IC 285200, IC 325181, IC 323993, IC 325740, IC 325794, IC 325835, IC 370475, IC 333121, IC 369836, IC 369859, IC 329028, IC 329055, IC 329076, IC420312, IC 420345, IC 373424, IC 373504, IC 373564, IC 449485, IC 577599, IC 577625, IC 577642, IC 426855, IC 426876, IC 426908 and IC 329909 exhibited the presence of crossover $\mathrm{g} x$ e interaction for harvest index.

The 23 accessions exhibited the presence of crossover interaction for number of effective tillers per plant for the accessions namely, IC 145316, IC 285200, IC 325181, IC 323993, IC 325794, IC 325835, IC 333121, IC 369836, IC 369859, IC 329028, IC 329055, IC 329076, IC420312, IC 420345, IC 373424, IC 373564, IC 449485, IC 577625, IC 577642, IC 426855, IC 426876, IC 426908 and IC 329909. 
Table.1 Heterogeneity $(\mathrm{H})$ test of response for the comparison of mean seed yield/plant $(\mathrm{g})$ against the standard variety RAJ. 171 along with $\mathrm{Q}^{+}$and $\mathrm{Q}^{-}$values for crossover interaction and adaptability parameters for the accessions

\begin{tabular}{|c|c|c|c|c|c|c|}
\hline \multirow[t]{2}{*}{ Accession } & \multicolumn{3}{|c|}{ Adaptability Parameters } & \multicolumn{3}{|c|}{ Against RAJ. 171} \\
\hline & $\mathrm{u}+\mathrm{d}_{\mathrm{i}}$ & $\mathrm{B}_{\mathrm{i}} \pm \mathrm{SE}$ & $\boldsymbol{\sigma}^{2} \mathrm{~d}_{\mathrm{i}}$ & $\mathrm{H}$ & $\mathrm{Q}^{+}$ & $\mathrm{Q}^{-}$ \\
\hline IC 329028 & 11.43 & $-0.35^{*} \pm 0.25$ & $0.09 *$ & $52.85^{\#}$ & $80.45^{\$}$ & 104.19 \\
\hline IC 139920 & 13.32 & $0.28 \pm 0.19$ & 0.02 & $94.11^{\#}$ & 38.95 & 43.27 \\
\hline IC 285200 & 9.45 & $0.58 * \pm 0.32$ & $0.32 *$ & $29.64^{\#}$ & $101.86^{\$}$ & 107.96 \\
\hline IC 323993 & 11.15 & $0.97 * \pm 0.43$ & $0.48^{*}$ & $63.35^{\#}$ & $93.55^{\$}$ & 161.89 \\
\hline IC 325181 & 14.09 & $1.39 * \pm 0.67$ & $0.60^{*}$ & $24.42^{\#}$ & 141.83 & $91.50^{\mathrm{s}}$ \\
\hline IC 325740 & 13.10 & $0.55^{*} \pm 0.43$ & $0.33^{*}$ & $47.30^{\#}$ & 167.74 & $131.26^{\$}$ \\
\hline IC 325815 & 7.98 & $-0.24 * \pm 0.12$ & $0.59^{*}$ & $102.87^{\#}$ & 94.65 & $91.97^{\$}$ \\
\hline IC 329055 & 13.48 & $0.11^{*} \pm 0.09$ & 0.03 & $36.57^{\#}$ & 45.76 & 62.53 \\
\hline IC 329076 & 12.21 & $0.97 * \pm 0.31$ & $0.76^{*}$ & $178.89^{\#}$ & $135.65^{\$}$ & 95.84 \\
\hline IC 329909 & 10.07 & $0.60 * \pm 0.36$ & $0.37^{*}$ & $53.16^{\#}$ & 98.45 & $186.97^{\$}$ \\
\hline IC 369859 & 12.98 & $-0.24 * \pm 0.08$ & 0.05 & $44.34^{\#}$ & 52.23 & 32.76 \\
\hline IC 370475 & 9.19 & $0.96^{*} \pm 0.49$ & $0.34 *$ & $93.75^{\#}$ & 169.59 & $109.81^{\$}$ \\
\hline IC 373424 & 9.90 & $-0.88^{*} \pm 0.32$ & $0.25^{*}$ & $134.35^{\#}$ & 67.22 & $141.61^{\$}$ \\
\hline IC 373504 & 12.52 & $-1.07^{*} \pm 0.52$ & $0.44^{*}$ & $95.17^{\#}$ & 118.59 & $92.43^{\$}$ \\
\hline IC 373564 & 12.35 & $0.93 * \pm 0.29$ & $0.22 *$ & $113.02^{\#}$ & 109.72 & $97.67^{\$}$ \\
\hline IC 420345 & 9.15 & $1.42 \pm 0.37$ & $0.61 *$ & $87.83^{\#}$ & 85.94 & $127.94^{\$}$ \\
\hline IC 426855 & 14.75 & $1.12 * \pm 0.34$ & $0.48^{*}$ & $65.14^{\#}$ & $132.61^{\$}$ & 72.34 \\
\hline IC 426876 & 8.87 & $0.97 * \pm 0.21$ & $0.53^{*}$ & $94.97^{\#}$ & 82.89 & $204.11^{\$}$ \\
\hline IC 525794 & 14.93 & $1.34 * \pm 0.42$ & 0.06 & $49.28^{\#}$ & 60.13 & 60.39 \\
\hline IC 577642 & 8.99 & $0.70 * \pm 0.23$ & 0.32 & $128.46^{\#}$ & $108.74^{\$}$ & 92.65 \\
\hline
\end{tabular}

\section{Grand Mean $9.08 \pm 1.21$}

\section{RAJ. $17111.43 \pm 0.89$}

- Significant at $\mathrm{P}<0.05$; \# $\mathrm{H}$ was significant against $\mathrm{x}^{2} 0.05$ at $\mathrm{s}-\mathrm{ldf}$, where $\mathrm{s}$ is the number of environments. \$ minimum of either $\mathrm{Q}^{+}$or $\mathrm{Q}^{-}$was significant against "e" value given by Gail and Simon (1985). 
Table.2 Accessions exhibiting significant *, \#H (heterogeneity of response), and $\mathrm{Q}^{+}$and $\mathrm{Q}^{-}$ against standard variety RAJ. 171

\begin{tabular}{|c|c|c|}
\hline Characters & $\mathbf{H}$ & $\mathbf{Q}^{+}$and $\mathbf{Q}^{-}$ \\
\hline Seed yield/plant (g) & $\begin{array}{l}\text { All accessions } \\
\text { except IC } 139920, \\
\text { IC } 329028 \text { and } \\
\text { IC420312 }\end{array}$ & $\begin{array}{l}\text { IC } 285200, \text { IC } 325181, \text { IC } 323993, \text { IC } 325740, \text { IC } \\
325794, \text { IC } 370475, \text { IC } 369836, \text { IC } 369859, \text { IC } 329028, \\
\text { IC } 329055, \text { IC } 329076, \text { IC } 420312, \text { IC } 420345, \text { IC } \\
373424, \text { IC } 373504, \text { IC } 373564, \text { IC } 449485, \text { IC } 577599 \text {, } \\
\text { IC } 577625, \text { IC } 577642, \text { IC } 426855, \text { IC } 426876, \text { IC } \\
426908, \text { IC } 329909 \text { ( } 24 \text { accessions) }\end{array}$ \\
\hline Biological yield/ plant (g) & $\begin{array}{l}\text { All accessions } \\
\text { except IC } 325835 \\
\text { and IC } 329076\end{array}$ & $\begin{array}{l}\text { IC } 145316, \text { IC } 285176, \text { IC } 285200, \text { IC } 325181, \text { IC } \\
323993, \text { IC } 325740, \text { IC } 325794, \text { IC } 325835, \text { IC } 333121 \text {, } \\
\text { IC } 369836, \text { IC } 369859, \text { IC } 329028, \text { IC } 329055 \text {, } \\
\text { IC } 420312, \text { IC } 373504, \text { IC } 373564, \text { IC } 449485, \text { IC } \\
577599, \text { IC } 577642, \text { IC } 426855, \text { IC } 426876, \text { IC } 329909 \\
\text { (22 accessions). }\end{array}$ \\
\hline Harvest index & $\begin{array}{l}\text { All accessions } \\
\text { except IC } 329028\end{array}$ & $\begin{array}{l}\text { IC } 145316, \text { IC } 285176, \text { IC } 285200, \text { IC } 325181, \text { IC } \\
323993, \text { IC } 325740, \text { IC } 325794, \text { IC } 325835, \text { IC } 370475, \\
\text { IC } 333121, \text { IC } 369836, \text { IC } 369859, \text { IC } 329028, \text { IC } \\
329055, \text { IC } 329076, \text { IC } 420312, \text { IC 420345, IC } 373424, \\
\text { IC } 373504, \text { IC } 373564, \text { IC 449485, IC 577599, IC } \\
577625, \text { IC 577642, IC 426855, IC 426876, IC 426908, } \\
\text { IC } 329909 \text { (29accessions) }\end{array}$ \\
\hline $\begin{array}{l}\text { Number of effective tillers } \\
\text { per plant }\end{array}$ & $\begin{array}{l}\text { All } 29 \text { accessions } \\
\text { except IC 577625, } \\
\text { IC } 420312, \quad \text { IC } \\
577625 .\end{array}$ & 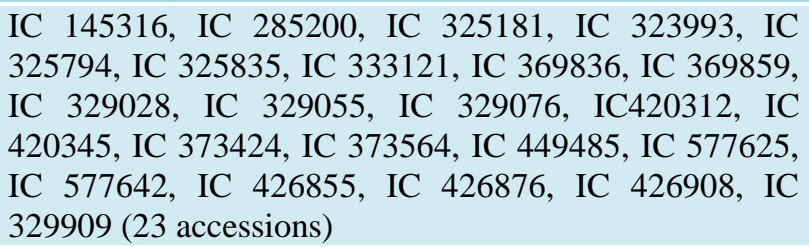 \\
\hline Plant height (cm.) & $\begin{array}{l}\text { All } 29 \text { accessions } \\
\text { except IC } 333121 \\
\text { IC420312 and IC } \\
577599\end{array}$ & 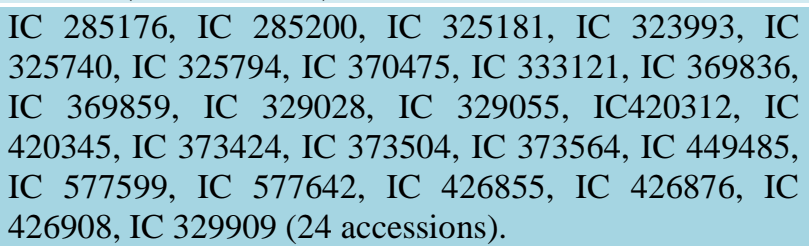 \\
\hline Flag leaf area $(\mathrm{cm})$ & $\begin{array}{lr}\text { All } & \text { accessions } \\
\text { except } & \text { IC } 145316 \\
\text { and IC } & 449485\end{array}$ & $\begin{array}{l}\text { IC } 145316, \text { IC } 285200, \text { IC } 325181, \text { IC } 325740, \text { IC } \\
325794, \text { IC } 325835, \text { IC } 370475, \text { IC } 333121, \text { IC } 369836, \\
\text { IC } 369859, \text { IC } 329028, \text { IC } 329055, \text { IC } 329076 \text {, } \\
\text { IC } 420312, \text { IC } 420345, \text { IC } 373424, \text { IC } 373564, \text { IC } \\
449485, \text { IC } 577625, \text { IC } 577642, \text { IC } 426855, \text { IC } 426876 \text {, } \\
\text { IC } 426908 \text { (23 accessions) }\end{array}$ \\
\hline Ear head length (cm) & $\begin{array}{l}\text { All accessions } \\
\text { except IC 285176, } \\
\text { IC } 285200 \text { and IC } \\
329909\end{array}$ & 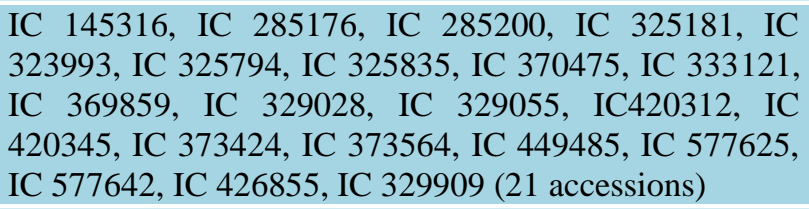 \\
\hline Days to $50 \%$ flowering & $\begin{array}{l}\text { All accessions } \\
\text { except IC } 323993, \\
\text { IC 373564 }\end{array}$ & $\begin{array}{l}\text { IC } 145316, \text { IC } 285176, \text { IC } 285200, \text { IC } 325181, \text { IC } \\
323993, \text { IC } 325794, \text { IC } 325835, \text { IC } 370475, \text { IC } 333121 \text {, } \\
\text { IC } 369836, \text { IC } 369859, \text { IC } 329028, \text { IC } 329055 \text {, } \\
\text { IC } 420312, \text { IC } 420345, \text { IC } 373424, \text { IC } 373504, \text { IC } \\
449485, \text { IC } 577599, \text { IC } 577642, \text { IC } 426855, \text { IC } 426876, \\
\text { IC } 426908 \text { (23 accessions). }\end{array}$ \\
\hline
\end{tabular}

*H was significant against $\mathrm{x}^{2} 0.05$ at s-1 df, where $\mathrm{s}$ is the number of environments. \# minimum of either $\mathrm{Q}^{+}$or $\mathrm{Q}^{-}$ was significant against "C" value given by Gail and Simmons (1985). 
The presence of cross over interaction showed by the accessions IC 285176, IC 285200, IC 325181, IC 323993, IC 325740, IC 325794, IC 370475, IC 333121, IC 369836, IC 369859, IC 329028, IC 329055, IC420312, IC 420345, IC 373424, IC 373504, IC 373564, IC 449485, IC 577599, IC 577642, IC 426855, IC 426876, IC 426908, IC 329909 for plant height. The 23 accessions had the presence of cross over interaction for flag leaf area of plant were IC 145316, IC 285200, IC 325181, IC 325740, IC 325794, IC 325835, IC 370475, IC 333121, IC 369836, IC 369859, IC 329028, IC 329055, IC 329076, IC420312, IC 420345, IC 373424, IC 373564, IC 449485, IC 577625, IC 577642, IC 426855, IC 426876, IC 426908. The 21 accessions expressed the presence of cross over interaction namely IC 145316, IC 285176, IC 285200, IC 325181, IC 323993, IC 325794, IC 325835, IC 370475, IC 333121, IC 369859, IC 329028, IC 329055, IC420312, IC 420345, IC 373424, IC 373564, IC 449485, IC 577625, IC 577642, IC 426855, IC 329909 (21 accessions) for number of ear head length. The 23 accessions IC 145316, IC 285176, IC 285200, IC 325181, IC 323993, IC 325794, IC 325835, IC 370475, IC 333121, IC 369836, IC 369859, IC 329028, IC 329055, IC420312, IC 420345, IC 373424, IC 373504, IC 449485, IC 577599, IC 577642, IC 426855, IC 426876, IC 426908 showed the presence of cross over interaction for days to $50 \%$ flowering. However, most of the accessions expressed the presence of crossover interaction but all accessions failed to exhibit crossover interaction for all traits against RAJ. 171 thus, presence or absence of crossover interaction was accession specific and trait specific (Rathore and Gupta, 1995). The accession IC 369836, IC 426855, IC103190, and IC 325181 in Kharif 2013 and 2015; and IC 369859. IC 325794, IC 329055 and, had significantly higher seed yield/plant than check RAJ 171 during kharif 2014.
The conclusion drawn from regression analysis and crossover and non-crossover interactions concept about identifying accessions having specific adaptability differs considerably. The accessions IC139920, IC 325181 and IC 426855 identified as potential yielder having specific adaptability on the basis of regression analysis also exhibited significant min (Q+ or Q-) against standard variety RAJ 171except IC139920 that had non-significant $\min (\mathrm{Q}+, \mathrm{Q}-)$ against RAJ. 171. On the other hand the nine accessions IC 369859, IC 325794, IC 329055, IC 139920, IC 325181 and IC 426855 identified as potential yielders having specific adapt ability on the basis of crossover and non-crossover interaction concept, failed to exhibit stable above average performance and responsiveness for seed yield/plant except IC 325181 and IC 426855.

A mention may be made of the accessions, IC 325181 and IC 426855 which have been identified as a high yielding ones having specific adaptability both by using regression analysis and crossover and non-crossover interaction concepts. These accessions gave significantly more mean seed yield/plant than the standard variety RAJ. 171. However during 2014 these had insignificant lower seed yield than RAJ. 171 Thus, accession IC325181 and IC426855 had specific adaptation rather than possessing general adaptation (Sharma, 1995).

\section{References}

Baker R. J. 1988. Test for crossover accession-environment interaction. Can. J. Plant SeL, 68 4: 405-410.

Eberhart S. A. and W. A. Russell. 1966. Stability parameters for comparing varieties. CropSci., 6: 36-40.

Gail M. and R. Simon. 1985. Testing for quantitative interaction in 
Schizophyllum commune. Analysis and character. Heredity, 27: 361-372.

Perkins J. M. and J. L. Jinks. 1968. Environmental and accessionenvironmental components 2 of variability IV. Non-linear interaction for multiple inbred lines. Heredity, 23: 525535.

Peto R. 1982. Statistical aspects of cancer trials. pp. 867-871. In: E. E. Halnan (ed.), Treatment of cancer, Chapman and Hall, London, U.K.
Rathore P. K. and V. P. Gupta. 1995. Crossover and non-crossover interactions and regression analysis for seed yield and its components in pea. Crop Improv, 21: 14-18.

Sharma R. K. 1995. Breeding lentil for response to additional nitrogen application. Crop Improv, 22: 139-141.

Virk D. S. and B. K. Mangat. 1991. Detection of crossover accession $\mathrm{x}$ environment interaction in pearlmillet. Euphytica, 52: 193-199.

\section{How to cite this article:}

Om Vir Singh, Kartar Singh and Neelam Shekhawat. 2018. Quantitative GXE Interaction Estimation in the Germplasm of Pearl Millet [Pennisetum glaucum (L.) R. Br.] in the Hot Arid Climate of Rajasthan. Int.J.Curr.Microbiol.App.Sci. 7(10): 3152-3158.

doi: https://doi.org/10.20546/ijcmas.2018.710.365 